\title{
Article
}

\section{Low-Cost 400 Gbps DR4 Silicon Photonics Transmitter for Short-Reach Datacenter Application}

\author{
Haike Zhu ${ }^{1, *}$, Sean Anderson ${ }^{1}{ }^{\circ}$, Nick Karfelt ${ }^{2}{ }^{\oplus}$, Lingjun Jiang ${ }^{2}$, Yunchu Li ${ }^{2}$, Robert Boeck ${ }^{2}$, \\ Hiroyuki Yamazaki ${ }^{1}$, Meng Wang ${ }^{3}$, Raju Kankipati ${ }^{4}$ and Richard Grzybowski ${ }^{2}$ \\ 1 MACOM Technology Solutions Inc., Allentown, PA 18195, USA; sean.anderson@macom.com (S.A.); \\ hiroyuki.yamazaki@macom.com (H.Y.) \\ 2 MACOM Technology Solutions Inc., Horseheads, NY 14845, USA; nick.karfelt@macom.com (N.K.); \\ lingjun.jiang@macom.com (L.J.); yunchu.li@macom.com (Y.L.); robert.boeck@macom.com (R.B.); \\ rich.grzybowski@macom.com (R.G.) \\ 3 MACOM Technology Solutions Inc., Ithaca, NY 14850, USA; meng.wang@macom.com \\ 4 MACOM Technology Solutions Inc., Lowell, MA 01851, USA; raju.kankipati@macom.com \\ * Correspondence: haike.zhu@macom.com
}

check for updates

Citation: Zhu, H.; Anderson, S.; Karfelt, N.; Jiang, L.; Li, Y.; Boeck, R.; Yamazaki, H.; Wang, M.; Kankipati,

R.; Grzybowski, R. Low-Cost 400 Gbps DR4 Silicon Photonics Transmitter for Short-Reach Datacenter Application. Nanomaterials 2021, 11, 1941. https://doi.org/ 10.3390/nano11081941

Academic Editor: Stefania Castelletto

Received: 28 May 2021

Accepted: 25 July 2021

Published: 28 July 2021

Publisher's Note: MDPI stays neutral with regard to jurisdictional claims in published maps and institutional affiliations.

\begin{abstract}
Targeting high-speed, low-cost, short-reach intra-datacenter connections, we designed and tested an integrated silicon photonic circuit as a transmitter engine. This engine can be packaged into an optical transceiver module which meets the QSFP-DD Form Factor, together with other electrical/optical components. We first present the design and performance of a high-speed silicon modulator, which had a 3-dB EO bandwidth of $>40 \mathrm{GHz}$ and an ER of $>5 \mathrm{~dB}$. We then incorporated the engine onto a test board and injected a 53.125 Gbaud PAM4 signal. Clear eye patterns were observed at the receiver with TDECQ $\sim 3 \mathrm{~dB}$ for all four lanes.
\end{abstract}

Keywords: datacom; integrated optics devices; silicon photonics; optical modulator; transmitter; PAM-4; QSFP-DD; 400GBASE-DR4

\section{Introduction}

Due to its compatibility with mature CMOS manufacturing techniques, compact size and cost effectiveness, integrated silicon photonics have been well developed as an engine for optical transceivers [1-4] and widely deployed in datacenters for high-speed, short-reach connections. Transceiver engines combine many elemental silicon photonics components, such as waveguides, splitters, I/O couplers, phase shifters and multiplexers (MUXs) and are able to process $100 \mathrm{~Gb} / \mathrm{s}$ or $400 \mathrm{~Gb} / \mathrm{s}$ signals, which currently dominate $500 \mathrm{~m}$ to $2 \mathrm{~km}$ intra-datacenter communications. For the transceiver architecture, according to IEEE standards, $100 \mathrm{~Gb} / \mathrm{s}$ can be realized using four lanes of $25 \mathrm{~Gb} / \mathrm{s}$ on-off keying (OOK) signal [5] or a single lane of $100 \mathrm{~Gb} / \mathrm{s}$ Pulse Amplitude Modulation four-level (PAM-4) signal over single-mode fiber (SMF). In contrast, $400 \mathrm{~Gb} / \mathrm{s}$ needs four lanes of $100 \mathrm{~Gb} / \mathrm{s}$ PAM-4 signals [6]. More recently, silicon photonic engines have been used for higher data rates, such as $200 \mathrm{~Gb} / \mathrm{s}$ per lane, for next generation $800 \mathrm{~Gb} / \mathrm{s}$ transceivers when heavy digital signal processing (DSP) is added [7]. Coherent modulation has also been applied to silicon photonics engines for datacenter connections, achieving over $500 \mathrm{~Gb} / \mathrm{s}$ per lane speed [8]. Moreover, another way to boost the data capacity of a silicon photonics engine is to integrate more lanes, if allowed by power consumption limits $[9,10]$.

Intra-datacenter connectivity at $400 \mathrm{~Gb} / \mathrm{s}$ is currently in the spotlight, and now is the right time for $400 \mathrm{~Gb} / \mathrm{s}$ links to replace $<100 \mathrm{~Gb} / \mathrm{s}$ or even $100 \mathrm{~Gb} / \mathrm{s}$ links. To optimize the $400 \mathrm{~Gb} / \mathrm{s}$ technology, significant research on III-V directly modulated lasers (DMLs) [11,12], externally modulated lasers (EMLs) [13,14] and silicon photonics-based Mach-Zehnder modulators (MZMs) has been conducted [15-20]. Generally, DML is the most cost-effective solution, with a small footprint, but it suffers serious frequency chirp at 
high data rates [21]; therefore, a slightly more complex DSP must be used, especially for longer-distance communication. EMLs have excellent performance in terms of bandwidth and insertion loss (IL), but the cost of introducing EML is relatively high and it also needs to be designed carefully for thermal stability [22]. Silicon photonics is also a low-cost, high-performance solution. However, due to the inherent high IL, it is usually used to cover $500 \mathrm{~m}$ to $2 \mathrm{~km}$, the 'mid-range' of the intra-datacenter links, whereas DMLs/EMLs are often seen in $2 \mathrm{~km}$ to $10 \mathrm{~km}$ or even $20 \mathrm{~km}$ links.

In our previous work, we experimentally demonstrated a $400 \mathrm{~Gb} / \mathrm{s}$ transmitter with a silicon photonics engine [23]. Due to insufficient modulator bandwidth, we applied shaping, pre-compensation and a peak-to-peak differential voltage as high as $5 \mathrm{~V}_{\mathrm{ppd}}$ at the transmitter side. When receiving the optical signal, we had to apply offline DSP with a digital square and filtering algorithm for timing recovery and a least mean square algorithm, with a 21-tap filter, in order to balance the complexity with system performance. However, after we redesigned the modulator, doubled its bandwidth and optimized our other silicon photonics components, we confirmed successful $400 \mathrm{~Gb} / \mathrm{s}$ signal transmission in our new silicon photonics engine that met the IEEE standard.

In this paper, we first illustrate a technical roadmap for building a low-cost silicon photonic transceiver with MACOM devices. Then, we discuss the design and performance of our modulator. After that, we present the measurements of a $400 \mathrm{~Gb} / \mathrm{s}$ DR4 transmitter when we attach the silicon photonics engine to an evaluation board. Finally, we summarize the results of our current product and show plans for test and design in future.

\section{MACOM's Silicon Photonics Roadmap}

Figure 1 schematically depicts a transceiver block diagram. In optical routing, our high output $(>20 \mathrm{dBm})$ laser chips, which are yield enhanced and cost reduced by etched facet technology [24,25], are first packaged in Transmit Optical Sub-Assembly (TOSA) or Transistor Outline can (TO-can) and the light is coupled into the silicon photonics engine using optical lenses. Then, the light is split into several lanes, modulated, multiplexed (following $100 \mathrm{G}$ Lambda MSA FR4 standards) and routed out to a fiber (array) as Tx. The laser chips can also be flip-chip bonded into the silicon photonics engines, as described in our previous work $[23,25]$. For $R x$, the optical signal is coupled into the engine chip through a fiber (array), TE polarized, de-multiplexed (following $100 \mathrm{G}$ Lambda MSA FR4 standards) and converted to an electrical signal by a Ge/Si photodetector [26].

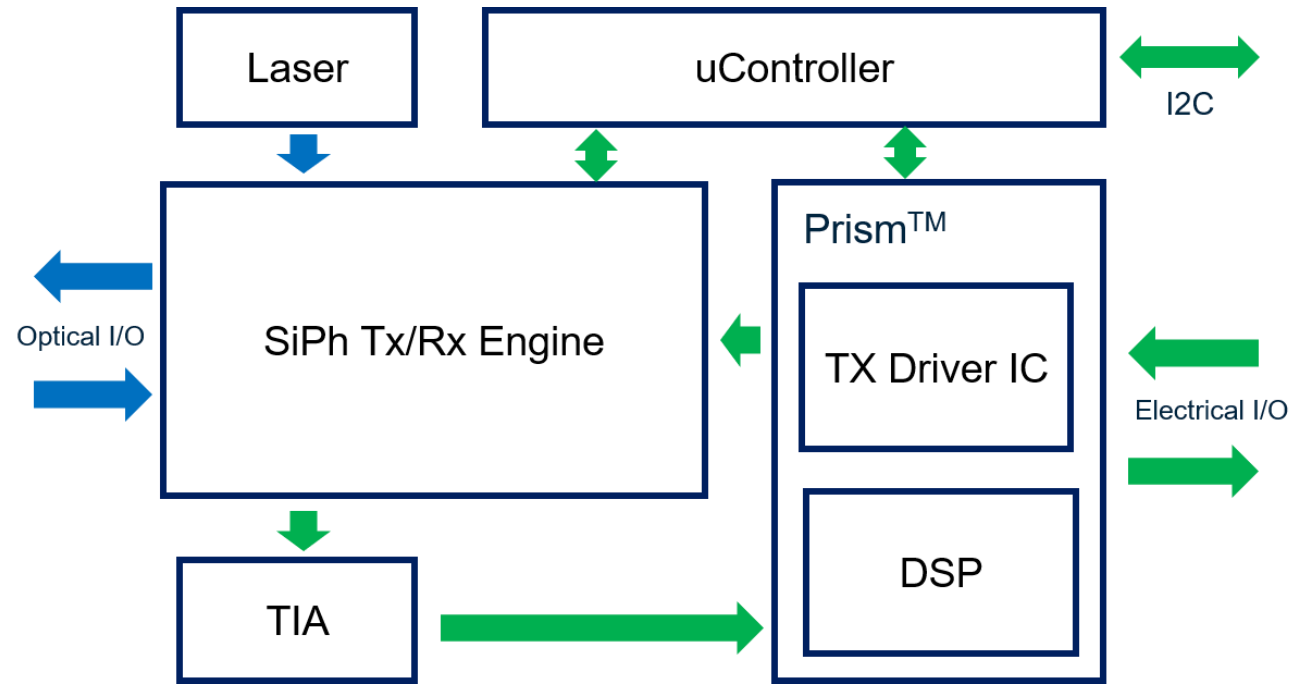

Figure 1. Way to build an optical transceiver using silicon photonics engine.

In electrical routing, the serial electrical signal is first sent into a MACOM Prism ${ }^{\mathrm{TM}}$ chip, where the DSP chip is co-packaged with the driver IC for pre-emphasis, PAM-4 mapping and linear amplification. Then, the amplified signal is fed into a silicon photonics 
engine through wire bonding as Tx. The microcontroller reads the monitor feedback from the silicon photonics engine and generates DC controls, such as modulator bias, modulator phase and MUX filter tuning vs. temperature. The microcontroller also manages the driver swing tuning and the data processing complexity in the Prism ${ }^{\mathrm{TM}}$ chip. For Rx, the received electrical signal is first amplified by a two-stage TIA (MAMF-03819) and then processed by the Prism ${ }^{\mathrm{TM}}$ chip for Feed Forward Equalization (FFE), Decision Feedback Equalization (DFE) and some other proprietary equalization before PAM-4 de-mapping. Finally, the recovered electrical signal goes to the serial interface. Note that the DSP is optimized for the $100 \mathrm{~Gb} / \mathrm{s}$ per lane silicon photonics engine for both Tx and Rx, providing lower latency data processing and low power consumption. The DSP is also able to activate real time KP4-FEC (forward error correction) (de-)coding, which is 'overclocking' the silicon photonics engine for $>100 \mathrm{~Gb} / \mathrm{s}$ per lane transmission.

\section{Modulator Design and Characterization}

Our modulator is based on the Mach-Zehnder Interferometer (MZI), which is insensitive to fabrication error and temperature changes, but with a relatively large device size. An optical cavity structure, such as microring (MR), theoretically consumes less power but needs smart designs to withstand the resonance perturbation [27] and nonlinearity [28].

In our design, the optical waveguide of the MZI was formed on a silicon-on-insulator (SOI) wafer and a light dose $\left(\sim 10^{17} \mathrm{~cm}^{-3}\right)$ of boron and phosphorus was injected to create the $\mathrm{PN}$ junction. The junction is reverse biased, to establish a depletion region that overlaps with the optical $\mathrm{TE}_{0}$ mode confined in the waveguide. The effective index of the waveguide is then modulated by the applied reversed bias that changes the depletion width. To balance the performance among the carrier drifting speed, dopant-induced optical loss and variation range of the effective index, we considered all factors such as: the waveguide geometry, doping profile and junction offset from the waveguide center. Outside of the waveguide, heavy doses $\left(\sim 10^{20} \mathrm{~cm}^{-3}\right)$ of boron and phosphorus were injected into the slab region to create ohmic contacts between the metals and PN junction.

As the PN junctions are always several millimeters long to achieve sufficient modulation depth, the traveling wave electrode (TWE) was carefully designed to meet both electric-optical phase matching and impedance matching. A polysilicon-based $50 \Omega$ termination resistor was integrated at the end of the TWE. Followed by the TWE, an NIN junction was embedded in the waveguide of each arm to form a low-loss thermal phase shifter, by which the MZI was tuned to quadrature. The MZM was finally buried in oxide dielectric layers when the fabrication processing was completed. A simplified cross-section view of the silicon MZM is shown in Figure 2.

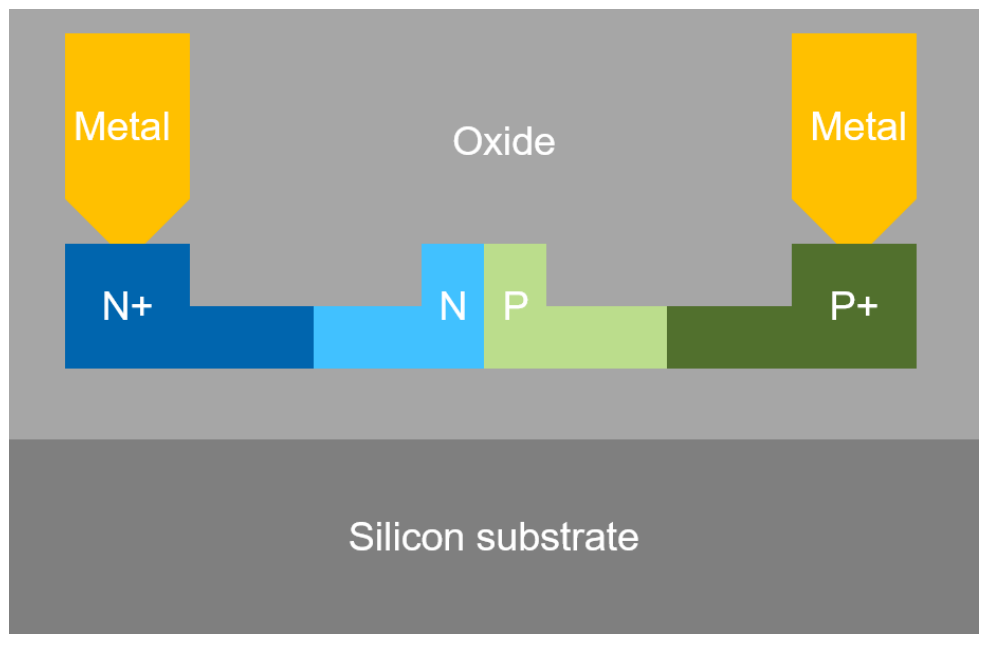

Figure 2. Cross-section view of the silicon photonics modulator. 
For the DC measurement, The MZM had an insertion loss of $<5 \mathrm{~dB}$ and $\mathrm{V}_{\mathrm{pi}} \times \mathrm{L}$ of $\sim 2.5 \mathrm{~V} . c m$ under $-2 \mathrm{~V}$ bias. The small signal electro-optical (EO) response of the MZM was characterized by a Vector Network Analyzer (VNA) with frequency sweeping from $100 \mathrm{MHz}$ to $50 \mathrm{GHz}$. Port 1 and Port 3 from the VNA were differentially paired and connected to each arm of the MZM and thus formed a push-pull driving scheme. The output optical signal was received by a $70 \mathrm{GHz}$ commercial InGaAs photodetector (11241-01P), which connected to Port 2 from the VNA. The optical wavelength was fixed at $1310 \mathrm{~nm}$, and the modulator was reverse-biased at $2 \mathrm{~V}$. The tested differential S11 response of the MZM is shown in Figure 3a. The reflection in the frequency range of $100 \mathrm{MHz}$ to $30 \mathrm{GHz}$ was $<-20 \mathrm{~dB}$ and slowly increased to $\sim-10 \mathrm{~dB}$ at higher frequencies, indicating a good impedance matching. The tested differential S21 response of the MZM is shown in Figure 3b. The 3-dB bandwidth of the MZM was $\sim 43 \mathrm{GHz}$. As the S21 curve had no sharp roll-off, the bandwidth compensation by FFE could be easily performed with fewer taps. Both the tested S11 and S21 curve match with the simulated data from our HFSS model, as shown in Figure 3a,b. In addition, the 6.4-dB electro-electrical (EE) bandwidth of the TWE was $\sim 45 \mathrm{GHz}$ as calculated, which suggests that the optical signal was efficiently modulated by the electrical signal, as a result of good phase matching.
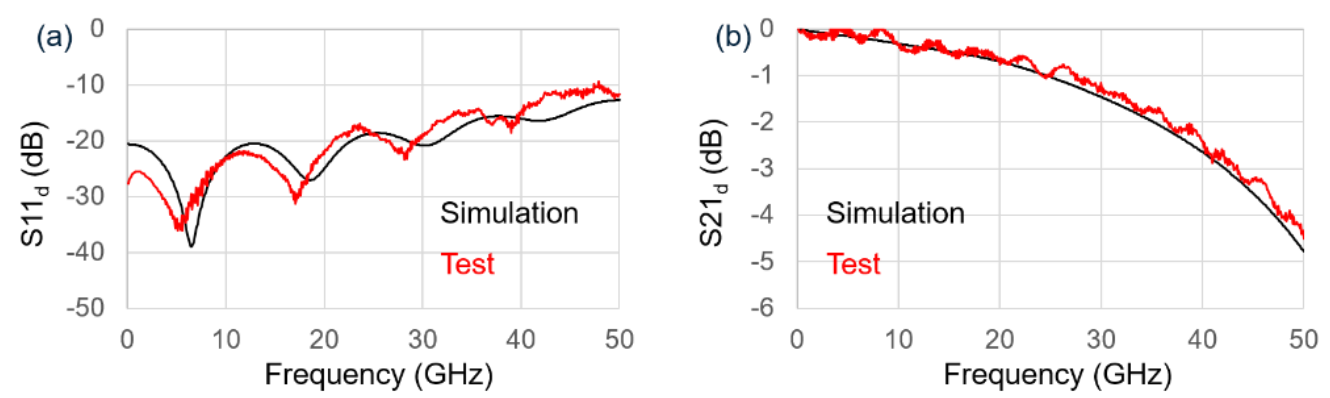

Figure 3. Test and simulation S-parameter results of MZM under differential drive: (a) reflection; (b) transmission.

A performance summary of silicon modulators is listed in Table 1.

Table 1. Key parameter comparison among different modulator types.

\begin{tabular}{cccccc}
\hline Ref. & $\begin{array}{c}\text { EO Bandwidth } \\
(\mathbf{G H z})\end{array}$ & $\begin{array}{c}\mathbf{V}_{\mathbf{p i}} \times \mathbf{L} \\
(\mathbf{V}-\mathbf{c m})\end{array}$ & $\begin{array}{c}\text { Loss } \\
(\mathbf{d B})\end{array}$ & $\begin{array}{c}\text { Data Rate } \\
(\mathbf{G b} / \mathbf{s})\end{array}$ & Type \\
\hline$[17]$ & 26 & 1.4 & 8 & $64(\mathrm{QPSK})$ & MZI \\
{$[18]$} & 20 & 0.8 & 10 & $256(\mathrm{DP}-16-\mathrm{QAM})$ & MZI \\
{$[28]$} & 50 & 0.52 & 4.2 & $112($ PAM-4) & MR \\
{$[29]$} & 35 & 1.8 & 5 & $72(\mathrm{NRZ})$ & SISCAP $^{1}$ \\
Our design & 43 & 2.5 & 5 & $106($ PAM-4) & MZI \\
\hline
\end{tabular}

${ }^{1}$ SISCAP: Silicon insulator silicon capacitor.

\section{DR4 Transmitter Test}

To analyze the general performance of the silicon photonics engine, we integrated it into an evaluation board, as shown in Figure 4. The engine design followed DR4 standards with a size of $6 \mathrm{~mm} \times 4 \mathrm{~mm}$. DC controls were added to the engine through top and bottom wire bonding, and AC signals were coupled to the engine through wire bonding on the right. The fibers were aligned to the edge couplers in the engine, and the TIA chip was bonded to the photodiode array in the engine. The AC inputs and TIA outputs went to GPPO connectors at the end of the evaluation board. The fiber array was inserted into the engine and fixed into the V-grooves, forming parallel optical lanes. The other end of the fiber array terminated in an MPO-12 connector. Note that the scale of the assembly, regardless of the temporary evaluation board, is compliant with the size constraints of the QSFP-DD MSA [30]. 


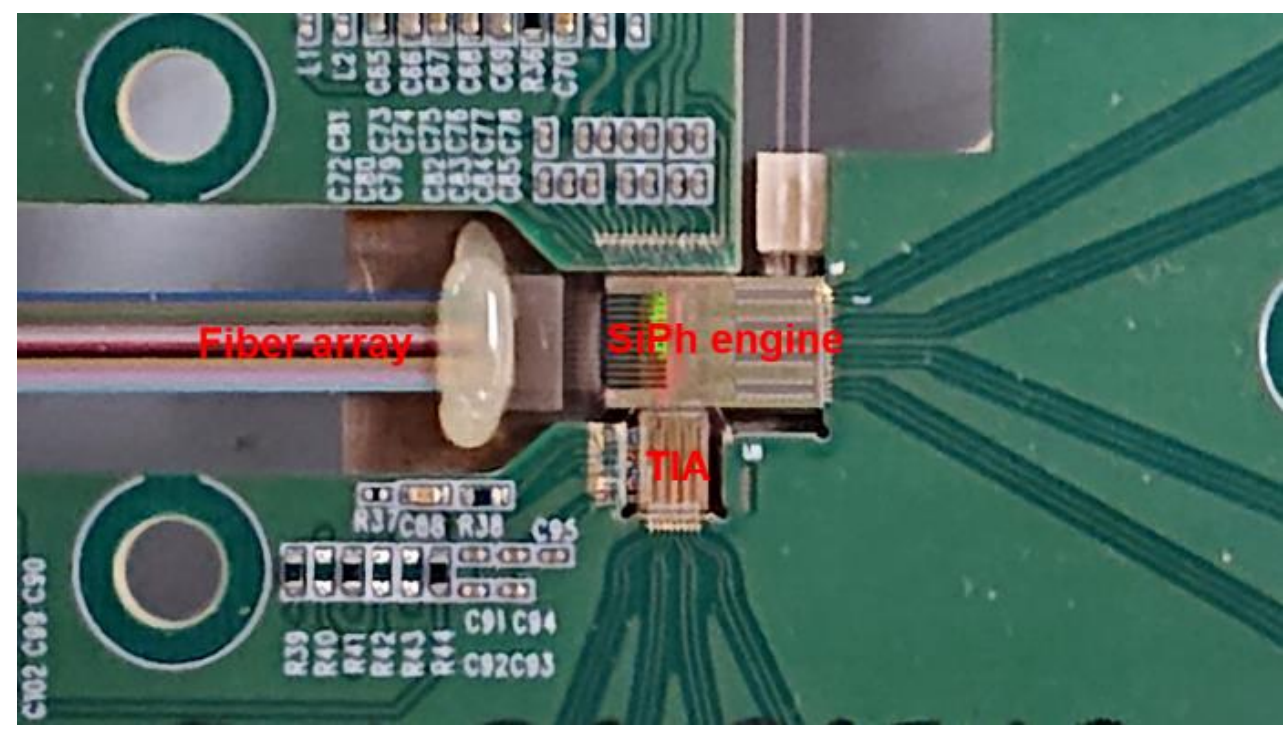

Figure 4. Microscope view of the assembled silicon photonics engine.

The large signal experiment setup is shown in Figure 5. Here, we only tested its performance as a transmitter. A bit error rate tester (BERT), which can work up to $64.8 \mathrm{GHz}$ clock speed, generates the PAM-4 signal and was pre-amplified by a BERT amplifier (Amp.) to $0.57 \mathrm{~V}_{\mathrm{pp}}$. Then, the signal was amplified to $1.8 \mathrm{~V}_{\mathrm{pp}}\left(3.6 \mathrm{~V}_{\mathrm{ppd}}\right)$ by a high-speed, linear driver and sent to the Balun, where the differential pair was formed. The electrical connection between Balun and device under test (DUT) was extremely short, in order to minimize skew between the differential pair. The differential signal was fed into the silicon photonics engine, lane by lane, through the evaluation board. After optical signal modulation, it was sent to a Digital Communication Analyzer (DCA) for data recovery. The System Impulse Response Correction (SIRC) was enabled to improve the response of the reference filter inside the DCA and to de-embed its bandwidth limitation. A 5-tap FFE was used when running the Transmitter and Dispersion Eye Closure Quaternary (TDECQ) algorithm.

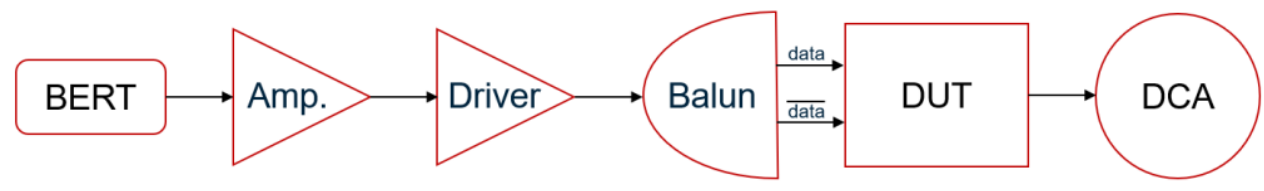

Figure 5. Experimental setup for transmitter PAM-4 signal test. BERT: bit error rate tester; Amp.: amplifier; DUT: device under test; DCA: Digital Communication Analyzer.

In Figure 6, clear open eyes are observed for all lanes in the silicon photonics engine at a data rate of $53.125 \mathrm{Gbaud} / \mathrm{s}$. To be specific, lane 1 has an Extinction Ratio (ER) of $5.4 \mathrm{~dB}$ and a TDECQ of $3.04 \mathrm{~dB}$; lane 2 has an ER of $5.3 \mathrm{~dB}$ and a TDECQ of $3.19 \mathrm{~dB}$; lane 3 has an ER of $5.3 \mathrm{~dB}$ and a TDECQ of $2.98 \mathrm{~dB}$; lane 4 has an ER of $5.0 \mathrm{~dB}$ and a TDECQ of $2.87 \mathrm{~dB}$. Thus, the PAM-4 eyes, in principle, would not approach the bit error rate limit on the receiver side. Note, that the high-speed response of the transmitter drops because of the relatively long and lossy RF routing between the driver and the modulator, including the GPPO cable and connector, metal trace on the evaluation board, and wire bonds. In a compact QSFP-DD package, where all the components shown in Figure 1 are attached on a high-speed substrate, we expect still better eye performance and lower TDECQ $<2 \mathrm{~dB}$. 

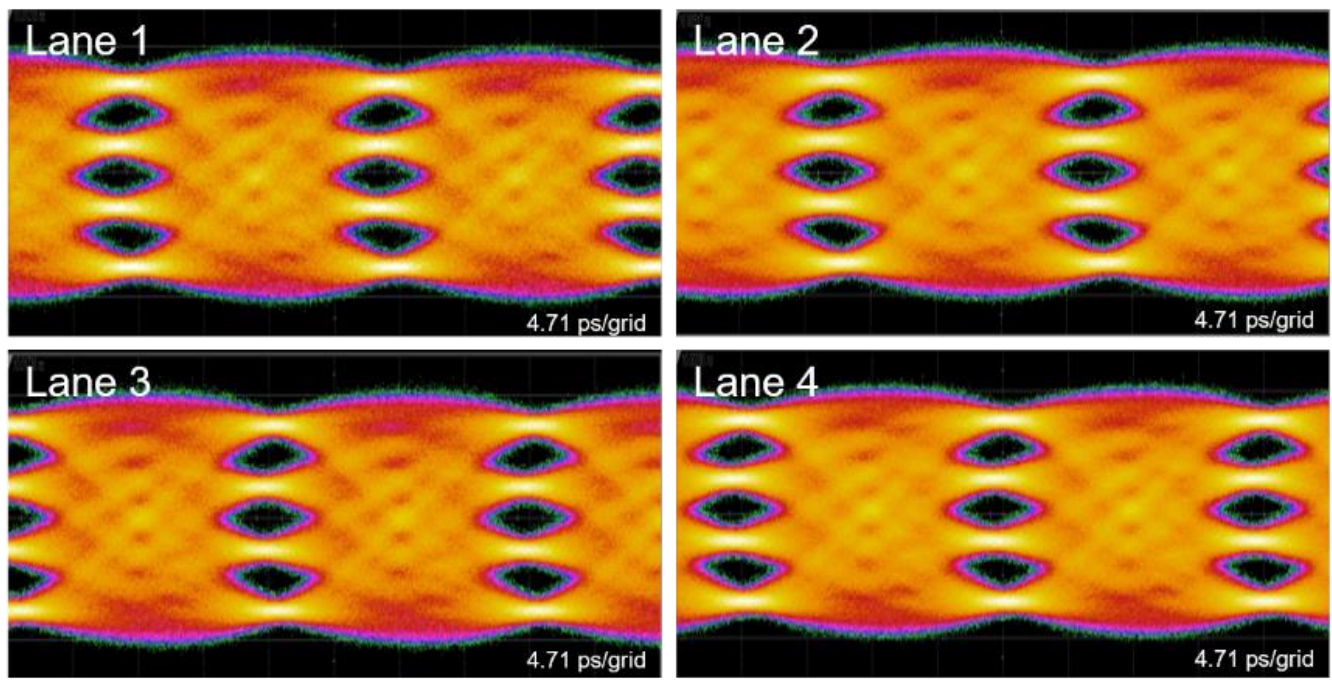

Figure 6. 53.125 Gbaud PAM-4 eye pattern from each lane of the transmitter.

Finally, as a $5 \mathrm{~dB}$ ER was achieved with a $1.8 \mathrm{~V}_{\mathrm{pp}}$ driving voltage and the optical loss is within $5 \mathrm{~dB}$, the MZM was functioning without consuming many resources electrically and optically. The power consumption of each MZM was $0.032 \mathrm{~W}\left((1.8 \mathrm{~V} / 2)^{2} / 50 \mathrm{ohm} \times 2\right)$ in the PN junction and $0.03 \mathrm{~W}$ in the thermal phase shifter. The power consumption of each driver was $0.4 \mathrm{~W}$. Therefore, $0.462 \mathrm{~W} \times 4=1.848 \mathrm{~W}$ power is used for modulators and drivers, which dominates the power consumption on the transmitter side. According to $400 \mathrm{G}$ transmitter power budget estimations of 4.6 5.5 W [31], there is enough of a margin for the micro controller and DSP.

\section{Summary and Prospect}

We have presented the MACOM silicon photonics transceiver architecture and tested the modulator and the silicon photonics engine as a DR4 transmitter. With all the MACOM components integrated in the transceiver, we were able to demonstrate a considerably cost-effective short reach link inside the datacenter. Thanks to the $>40 \mathrm{GHz}$ high bandwidth of the MZM, $4 \times 100 \mathrm{~Gb} / \mathrm{s}$ PAM-4 signals were transmitted and recovered with a low TDECQ of $\sim 3 \mathrm{~dB}$.

Our future study will be focusing on characterizing the receiver part of the silicon photonics engine, putting the transceiver on an evaluation board in a short reach link and packaging all the components in a QSFP-DD defined module as a reference prototype design for datacenter applications.

Author Contributions: Investigation, data curation and writing—original draft preparation, H.Z.; methodology, H.Z., S.A., L.J., Y.L., R.B., M.W. and H.Y.; software and validation, N.K.; writingreview and editing, R.B., L.J., R.K. and R.G.; supervision and project administration, R.G. All authors have read and agreed to the published version of the manuscript.

Funding: This research received no external funding.

Data Availability Statement: Not applicable.

Acknowledgments: The authors would like to thank Bart Zeydel from MACOM connectivity BU for important discussions.

Conflicts of Interest: The authors declare no conflict of interest. 


\section{References}

1. Abrams, N.C.; Cheng, Q.; Glick, M.; Jezzini, M.; Morrissey, P.; O’Brein, P.; Bergman, K. Silicon Photonic 2.5D Multi-Chip Module Transceiver for High-Performance Data Centers. J. Lightw. Technol. 2020, 38, 3346-3357. [CrossRef]

2. Pitris, S.; Moralis-Pegios, M.; Alexoudi, T.; Ban, Y.; Heyn, P.D.; Campenhout, J.V.; Lambrecht, J.; Rmon, H.; Yin, X.; Bauwelinck, J.; et al. O-Band Silicon Photonic Transmitters for Datacom and Computercom Interconnects. J. Lightw. Technol. 2019, 37, 5140-5148. [CrossRef]

3. Liljeberg, T. Silicon photonics and the future of optical connectivity in the data center. In Proceedings of the IEEE Optical Interconnects Conference, Santa Fe, NM, USA, 5-7 June 2017.

4. Hayashi, T.; Mekis, A.; Nakanishi, T.; Peterson, M.; Sahni, S.; Sun, P.; Freyling, S.; Armijo, G.; Sohn, C.; Foltz, D.; et al. End-to-End Multi-Core Fibre Transmission Link Enabled by Silicon Photonics Transceiver with Grating Coupler Array. In Proceedings of the European Conference on Optical Communication, Gothenburg, Sweden, 17-21 September 2017.

5. 100G PSM4 MSA. Available online: http://www.psm4.org/ (accessed on 28 May 2021).

6. 100G Lambda MSA. Available online: https://100glambda.com/ (accessed on 28 May 2021).

7. Zhang, H.; Li, M.; Zhang, Y.; Zhang, D.; Liao, Q.; He, J.; Hu, S.; Zhang, B.; Xiao, X.; Qi, N.; et al. 800 Gbit/s transmission over $1 \mathrm{~km}$ single-mode fiber using a four-channel silicon photonic transmitter. Photonics Res. 2020, 8, 1776-1782. [CrossRef]

8. Ahmed, A.H.; Moznine, A.E.; Lim, D.; Ma, Y.; Rylyakov, A.; Shekhar, S. A Dual-Polarization Silicon-Photonic Coherent Transmitter Supporting $552 \mathrm{~Gb} / \mathrm{s} /$ wavelength. IEEE J. Solid-State Circuits 2020, 55, 2597-2608. [CrossRef]

9. Tanaka, Y. High-speed and large-capacity integrated silicon photonics technologies. In Proceedings of the Proceedings SPIE 11308, Metro and Data Center Optical Networks and Short-Reach Links III, San Francisco, CA, USA, 31 January 2020.

10. Bernabé, S.; Wilmart, Q.; Hasharoni, K.; Hassan, K.; Thonnart, Y.; Tissier, P.; Désières, Y.; Olivier, S.; Tekin, T.; Szelag, B. Silicon photonics for terabit/s communication in data centers and exascale computers. Solid State Electron. 2021, 179, 1-25. [CrossRef]

11. Saarela, A.; Melanen, P.; Vilokkinen, V.; Kuusela, L.; Uusimaa, P.; Sipilä, P.; Ulkuniemi, R.; Mäkinen, O. High temperature AlGaInAs-based 25g DML-DFB lasers operating in O-band for data center use. In Proceedings of the Proceedings SPIE 11712, Metro and Data Center Optical Networks and Short-Reach Links IV, online, 5 March 2021.

12. Che, D.; Matsui, Y.; Schatz, R.; Rodes, R.; Khan, F.; Kwakernaak, M.; Sudo, T. 200-Gb/s Direct Modulation of a 50-GHz Class Laser With Advanced Digital Modulations. J. Lightw. Technol. 2021, 39, 845-852. [CrossRef]

13. Lin, Y.H.; Lin, H.S.; Wu, W.L.; Tsai, C.T.; Cheng, C.H.; Shih, T.T.; Lin, G.R. 100-Gbit/s/ $\lambda$ EML Transmitter and PIN-PD+TIA Receiver-Based Inter-Data Center Link. J. Lightw. Technol. 2020, 38, 2144-2151. [CrossRef]

14. Naoe, K.; Nakajima, T.; Nakai, Y.; Yamaguchi, Y.; Sakuma, Y.; Sasada, N. Advanced InP laser technologies for 400G and beyond hyperscale interconnections. In Proceedings of the Proceedings SPIE 11356, Semiconductor Lasers and Laser Dynamics IX, online, 1 April 2020.

15. Liao, L.; Samara-Rubio, D.; Morse, M.; Liu, A.; Hodge, D.; Rubin, D.; Keil, U.; Frank, T. High speed silicon Mach-Zehnder modulator. Opt. Express 2005, 13, 3129-3135. [CrossRef] [PubMed]

16. Tu, X.; Liow, T.; Song, J.; Luo, S.; Fang, Q.; Yu, M.; Lo, G. 50-Gb/s silicon optical modulator with traveling-wave electrodes. Opt. Express 2013, 21, 12776-12782. [CrossRef] [PubMed]

17. Zhu, H.; Zhou, L.; Wang, T.; Wong, C.; Zhou, Y.; Yang, R.; Li, Y.; Chen, J. Optimized silicon QPSK modulator with 64-Gb/s modulation speed. IEEE Photonics J. 2015, 7, 1-6. [CrossRef]

18. Ishikura, N.; Goi, K.; Zhu, H.; Illarionov, M.; Ishihara, H.; Oka, A.; Oda, T.; Masuko, K.; Ori, T.; Ogawa, K.; et al. Transmission Characteristics of 32-Gbaud PDM IQ Monolithic Silicon Modulator Operating with 2-VPPD Drive Voltage. In Proceedings of the European Conference on Optical Communication, Dusseldorf, Germany, 18-22 September 2016.

19. Xiao, X.; Li, M.; Wang, L.; Chen, D.; Yang, Q.; Yu, S. High speed silicon photonic modulators. In Proceedings of the Optical Fiber Communications Conference and Exhibition, Los Angeles, CA, USA, 19-23 March 2017.

20. Rahim, A.; Hermans, A.; Wohlfeil, B.; Petousi, D.; Kuyken, B.; Thourhout, D.V.; Baets, R.G. Taking silicon photonics modulators to a higher performance level: State-of-the-art and a review of new technologies. Adv. Photonics 2021, 3, 024003. [CrossRef]

21. Zhang, K.; Zhuge, Q.; Xin, H.; Hu, W.; Plant, D. Performance comparison of DML, EML and MZM in dispersion-unmanaged short reach transmissions with digital signal processing. Opt. Express 2018, 26, 34288-34304. [CrossRef] [PubMed]

22. Dai, X.; Debregeas, H.; Nguyen, T.D.H.; Lelarge, F.; Gentner, J. Uncooled 1.55 $\mu \mathrm{m}$ Electro-Absorption Modulated Laser at 28Gb/s with high power and low Vpp for datacom. In Proceedings of the European Conference on Optical Communication, Dublin, Ireland, 22-26 September 2019.

23. Zhong, K.; Mo, J.; Grzybowski, R.; Lau, A.P.T. 400 Gbps PAM-4 Signal Transmission Using a Monolithic Laser Integrated Silicon Photonics Transmitter. In Proceedings of the Optical Fiber Communication Conference and Exhibition, San Diego, CA, USA, 3-7 March 2019.

24. Behfar, A.; Schremer, A.; Hwang, J.; Stagarescu, C.; Morrow, A.; Green, M. Etched facet technology for GaN and blue lasers. In Proceedings of the SPIE 6121, Gallium Nitride Materials and Devices, San Jose, CA, USA, 3 March 2006.

25. Grzybowski, R.; Martin, A. MACOM's L-PIC ${ }^{\text {TM }}$ (Laser Integrated PIC) Platform Using Self-Aligned Etch Facet Technology $\left(\right.$ SAEFT $\left.^{\mathrm{TM}}\right)$ For Data Center Networks. In Proceedings of the Photonic Networks and Devices, New Orleans, LA, USA, 24-27 July 2017; p. NeW1B-4. 
26. Benedikovic, D.; Virot, L.; Aubin, G.; Hartmann, J.; Amar, F.; Roux, X.L.; Alonso-Ramos, C.; Cassan, E.; Marris-Morini, D.; Fédéli, J.; et al. Silicon-germanium receivers for short-wave-infrared optoelectronics and communications. Nanophotonics 2020, 10, 1059-1079. [CrossRef]

27. Guha, B.; Kyotoku, B.B.C.; Lipson, M. CMOS-compatible athermal silicon microring resonators. Opt. Express 2010, 18, $3487-3493$. [CrossRef] [PubMed]

28. Li, H.; Balamurugan, G.; Sakib, M.; Kumar, R.; Jayatilleka, H.; Rong, H.; Jaussi, J.; Casper, B. 12.1 A 3D-Integrated Microring-Based $112 \mathrm{~Gb} / \mathrm{s}$ PAM-4 Silicon-Photonic Transmitter with Integrated Nonlinear Equalization and Thermal Control. In Proceedings of the IEEE International Solid-State Circuits Conference, San Francisco, CA, USA, 16-20 February 2020.

29. Zhang, W.; Debnath, K.; Chen, B.; Li, K.; Liu, S.; Ebert, M.; Reynolds, J.D.; Khokhar, A.Z.; Littlejohns, C.; Byers, J.; et al. High Bandwidth Capacitance Efficient Silicon MOS Modulator. J. Lightw. Technol. 2021, 39, 201-207. [CrossRef]

30. QSFP-DD MSA Group. Available online: http:/ /www.qsfp-dd.com/ (accessed on 28 May 2021).

31. Minkenberg, C.; Krishnaswamy, R.; Zilkie, A.; Nelson, D. Co-packaged datacenter optics: Opportunities and challenges. IET Optoelectron. 2020, 15, 77-91. [CrossRef] 